\title{
Manual de uso de redes sociales
}

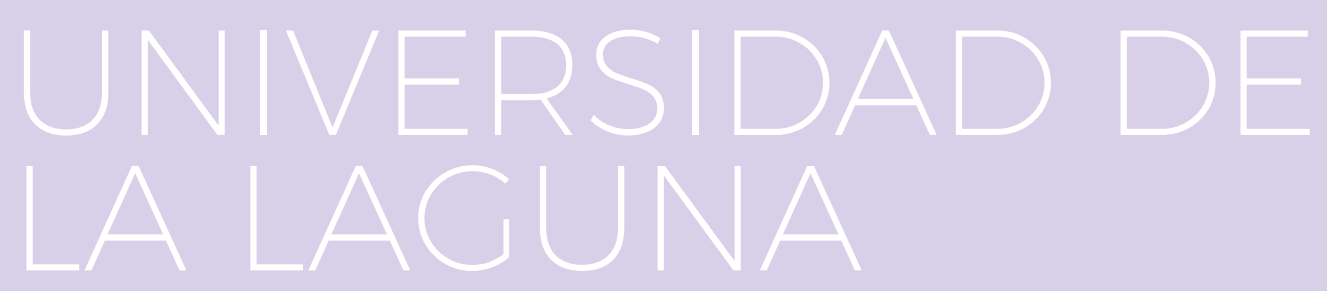

Gabinete de Comunicación

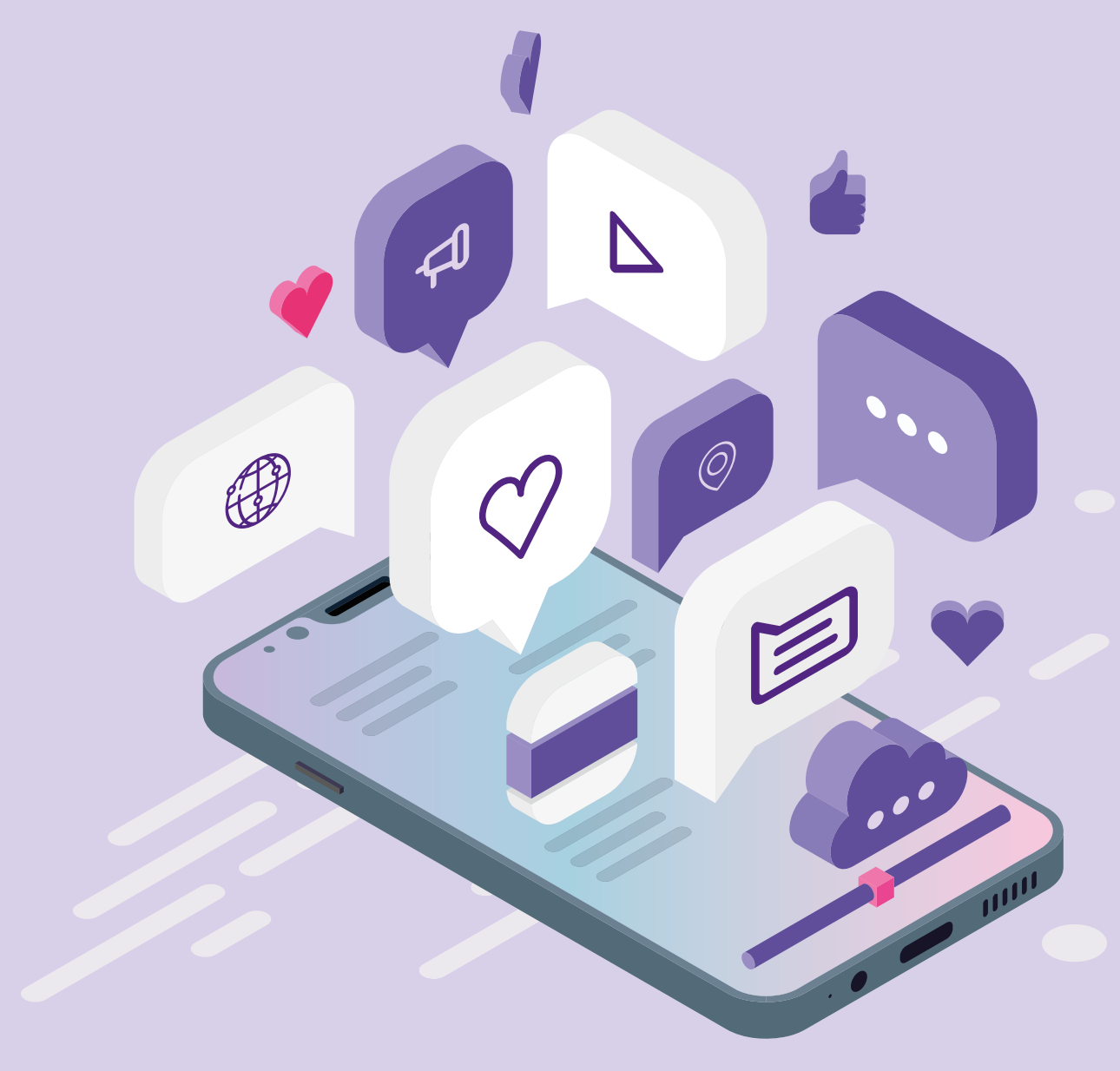




\section{Universitad \\ de La Laguna}

https://doi.org/10.25145/b.UsoRedesSoc.2021

\section{Gabinete de Comunicación}

Pabellón de Gobierno, C/ Padre Herrera s/n

Apartado Postal 456

38200, San Cristóbal de La Laguna

Santa Cruz de Tenerife - España

Teléfono: (+34) 922319462 / 9530

www.ull.es/servicios/comunicacion 


\section{Presentación}

\section{Creación de una cuenta en redes sociales}

1.1. Procedimiento de solicitud de altas de cuentas en redes sociales

1.2. Recomendaciones para la creación de redes

$$
\begin{aligned}
& \text { 1.2.1. Nombre de la cuenta } \\
& \text { 1.2.2. Biografía } \\
& \text { 1.2.3. Identidad visual/Marca de la } \\
& \text { Universidad de La Laguna }
\end{aligned}
$$

1.3. Elección del email o móvil de recuperación de cuenta

1.4. Cuentas inactivas

\section{Política de etiquetas y menciones}

2.1. Menciones

2.1.1. Criterios generales para la mención 2.2. Uso de hashtags

\section{Consejos y normas de estilo en la redacción en} redes sociales

\subsection{Contenidos}

3.1.1. Tipo de contenido gráfico (derechos de autor)

3.2. Actualización y mantenimiento

3.3. Gestión de comentarios y mensajes directos

3.3.1.Respuesta en público o en privado

3.4. Gestión de crisis

3.5. Análisis estadístico

\section{Facebook}

\section{Twitter}

\section{Instagram}

\section{Youtube}

\section{Linkedin}

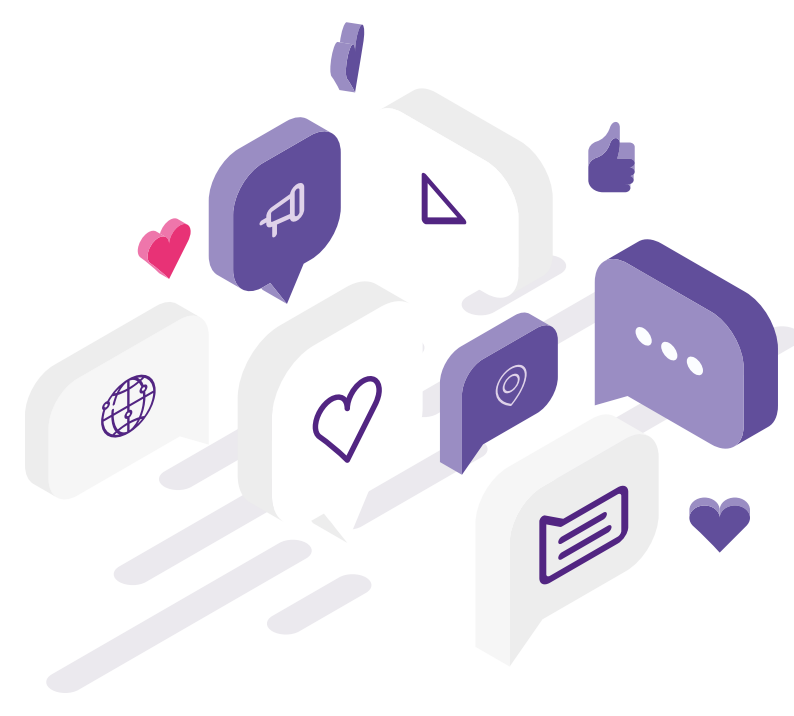


Las redes sociales han supuesto una revolución en el mundo de las comunicaciones, permitiendo a personas e instituciones establecer contacto con sus públicos de una manera rápida, ágil y sin necesidad de intermediarios. Sus ventajas son evidentes y ello ha propiciado que, especialmente en los últimos años, prácticamente todas las organizaciones posean perfiles en las plataformas más populares.

Sin embargo, el uso de redes sociales también entraña una serie de peligros y dificultades que no pueden ser obviadas. Estos nuevos medios 2.0 pueden ser fuentes de información, pero también de bulos, y son tan útiles para divulgar contenidos relevantes y de interés social como insultos y difamaciones. Por tanto, es necesario tener un cuidado exquisito no solo con lo que se publica, sino con el modo de hacerlo y también con lo que se contesta porque, como se suele decir, "la reputación tarda años en conseguirse y basta un minuto para perderla".

Estas dificultades se acentúan si se trata de una cuenta institucional, pues en ese caso las comunicaciones que de ella emanen se considerarán la postura oficial de la entidad, por lo que sus consecuencias atañen no solo a una persona, sino a todo un colectivo.

La Universidad de La Laguna, al igual que sucede en prácticamente todas las instituciones de educación superior, posee cuentas oficiales en diferentes redes sociales que están administradas desde el Gabinete de Comunicación. Pero también existe una amplia variedad de cuentas creadas por entidades y colectivos adscritos a la institución que funcionan de manera independiente.
Ese ecosistema de redes sociales puede ser una fortaleza institucional, pero para ello es necesario que actúe de manera coordinada. No se trata de que todos los perfiles estén controlados por las mismas personas, lo cual sería materialmente imposible, sino de que todos posean un marco común de actuación con unas normas claras.

Se trata de que, independientemente de quién sea la persona responsable los mensajes publicados por los perfiles dependientes de la Universidad de La Laguna, así como las respuestas que se den desde ellos, tengan un tono y características similares. Porque, al fin y al cabo, aunque cada entidad tiene su independencia, al final todas están bajo un mismo paraguas institucional.

Este manual nace con el objetivo de establecer ese marco común, ser un libro de estilo que despeje dudas acerca de cómo actuar en redes sociales desde los perfiles institucionales. Ha sido desarrollado teniendo en cuenta la propia experiencia del Gabinete de Comunicación como compartiendo experiencias con profesionales de otros centros.

Creemos que sus indicaciones son claras, lógicas y, sobre todo, útiles para que todas las cuentas institucionales de la Universidad de La Laguna remen en la misma dirección y ayuden a mantener una reputación online adecuada a lo que se espera de una universidad pública con tanto arraigo en su comunidad como es la nuestra. 


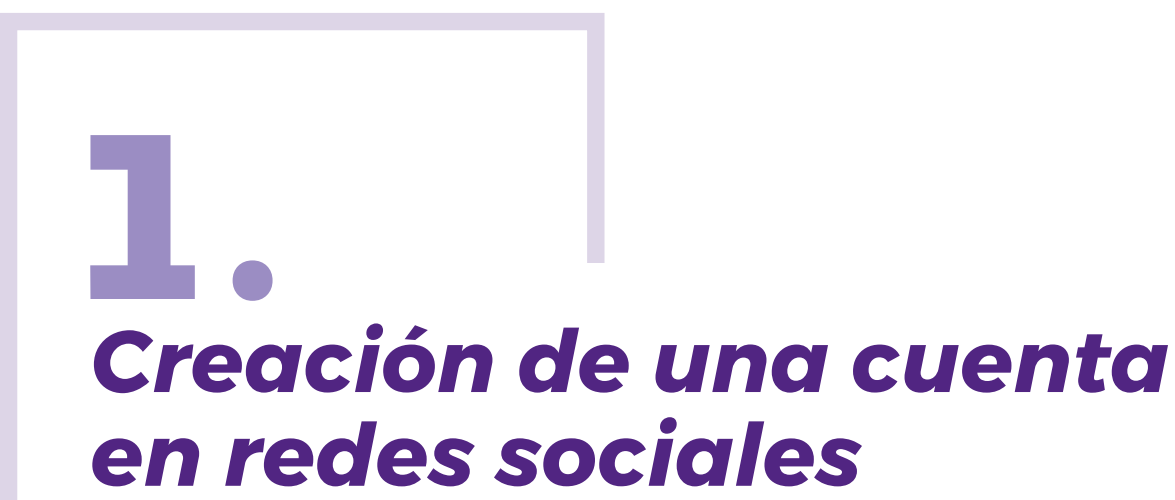

La creación de una cuenta en redes sociales vinculada a la Universidad de La Laguna no debe verse como una acción nimia e irrelevante. Con el paso de los años, y sobre todo con el auge de las redes como una forma de comunicación directa y sencilla, se ha procedido a la creación de cientos de cuentas en torno a esta institución académica por parte de gestores de forma independiente y autónoma. Esta situación ha dado como resultado que un elevado número de cuentas haya quedado en el olvido, sin ser actualizadas, obsoletas y que, a la postre, producen confusión o incluso desinformación por parte de los usuarios que reclaman comunicarse con la Universidad de La Laguna. Otras, por contra, están plenamente activas y ofrecen una imagen de la institución académica como centro pujante, vivo, en constante transformación.

Este manual de uso se ha elaborado bajo la firme convicción de que se puede comunicar a través de redes sociales de forma satisfactoria y tratando siempre de llegar al mayor número de usuarios posible. Por este motivo, uno de los grandes ejes dentro de este documento ha de ser el compromiso unánime de los gestores de redes vinculadas a la universidad de seguir la línea estilística que se describirá en los siguientes párrafos.

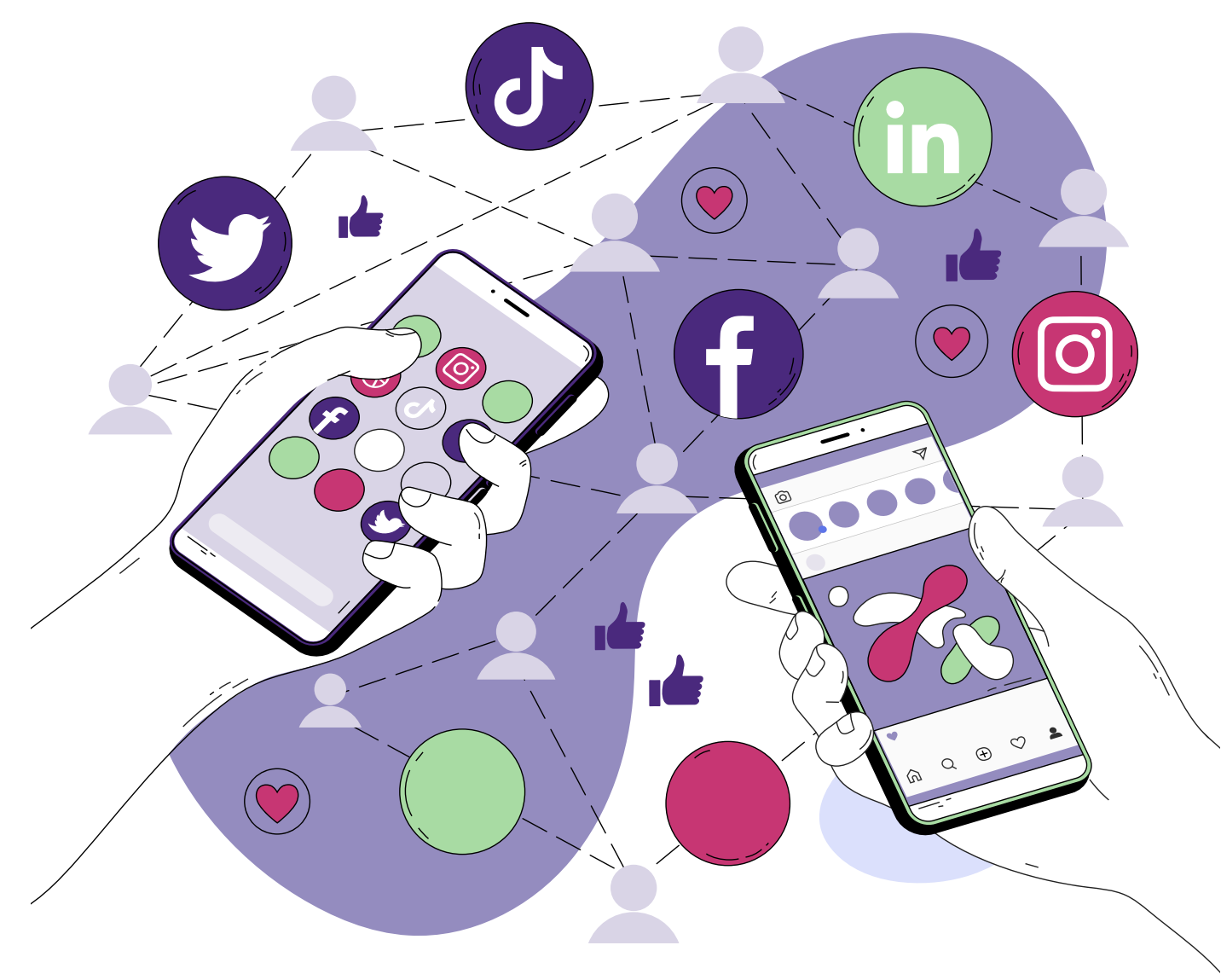




\subsection{PROCEDIMIENTO DE SOLICITUD DE ALTAS DE CUENTAS EN REDES SOCIALES}

Para empezar, previamente a la creación de una cuenta en redes sociales, se ha de remitir una petición al Gabinete de Comunicación (web@ull. es), órgano responsable que analizará cada una de estas cuestiones, explicando de forma razonada por qué se debe abrir un nuevo perfil en las redes sociales. De esta manera, este servicio llevará a cabo una reflexión sosegada y justificada acerca de la viabilidad de esta nueva cuenta. Para esta cuestión se recomienda contestar a las siguientes preguntas:

\section{$\odot$}

¿Cuál es el objetivo de esta cuenta?

¿Qué valor original y nuevo aportará a los usuarios?

¿Qué la diferencia de las cuentas institucionales ya creadas?

¿Cada cuánto tiempo se va a crear nuevo contenido?

¿Cubrirá un objetivo a largo plazo (hay que evitar la creación de redes "temporales", por ejemplo, de un evento concreto que tiene fecha final)?

¿Cuántas personas van a encargarse de la gestión? ¿Poseen recursos materiales (fotografía/vídeo)? ¿Podrán dar respuesta a las preguntas que les realicen los seguidores?

¿Cuál será el correo electrónico (@ull.es) que va a estar vinculado al perfil que se va a crear?

¿Cuál es el público al que se dirigen?

¿En qué redes sociales se quiere tener presencia?
Tras ser enviada la petición con toda esta información, si el Gabinete de Comunicación lo acepta, posteriormente el gestor o gestora habrá de rellenar un formulario en el que se señalarán algunos datos relevantes sobre el responsable de la red social que se va a poner en marcha. Si se diera el caso de que se ha creado una cuenta y no se ha registrado en este formulario, le rogamos que lo haga.

La decisión de comenzar a trabajar con una cuenta en redes sociales o no residirá en distintas cuestiones como la capacidad de creación de material original y único, la posibilidad de desarrollar contenido a diario, así como dar respuestas a las cuestiones que remitan los usuarios, y por supuesto, que no exista ya una cuenta que publique el mismo contenido. Si estas circunstancias impidieran crear una cuenta, siempre estarán a disposición de quien lo necesite, dentro de la comunidad universitaria, los canales institucionales que actualmente poseen miles de seguidores en las distintas plataformas (Facebook, Twitter, Instagram, Linkedin y Youtube).

\subsection{RECOMENDACIONES PARA LA CREACIÓN DE REDES}

1.2.1. Nombre de la cuenta

La elección del nombre de la cuenta así como su usuario ha de otorgar la mejor descripción posible. Por este motivo, tendrá que ser un nombre corto, de no más de 15 caracteres, que no emplee nomenclaturas confusas, que evite el uso de números o caracteres extraños (puntos, guiones, barras, etc.), y, por supuesto, que utilice la denominación más conocida por el público. 
Además, aunque no es lo más recomendable, si el nombre del servicio fuera demasiado largo, se pueden usar sus siglas.

A la hora de crear un nuevo perfil siempre se pueden emplear herramientas como checkusernames.com para tener una idea de qué nombres están disponibles.

\subsubsection{Biografía}

El texto de la biografía describirá de forma corta qué se va a encontrar el usuario o usuaria en la cuenta. Además, sería interesante que mencionara el nombre completo del servicio, así como que introdujera que pertenece a la Universidad de La Laguna. También en la descripción sería conveniente aportar un enlace a la página oficial de la institución.

\subsubsection{Identidad visual/Marca de la Universidad de La Laguna}

Esta institución académica cuenta con un Manual de identidad corporativa que rige cómo ha de ser el uso de la marca de la Universidad de La Laguna. No obstante, al centrarnos en las redes sociales, en la mayoría de los casos, dependiendo de los tamaños y especificaciones de cada plataforma, las cuentas han de seguir estos criterios:

- La imagen que aparecerá en el perfil tendrá que ser la del logo del servicio, centro, departamento, instituto, etc. que corresponda. Se podrán encontrar los logos en el siguiente enlace. También es válido el uso del logo tal y como se muestra en las imágenes de ejemplo. Si no dispusiera de logo propio dentro del catálogo del que dispone la Universidad de La Laguna, por favor, consúltelo con el Gabinete de Comunicación (web@ull.es).

- Tal y como define el "Manual de identidad corporativa" no se podrá hacer uso de submarcas o logos propios.

- Aunque no todas las redes sociales la tienen (es el caso de Instagram, por ejemplo), sería recomendable que la imagen de portada que se utilice vaya acorde con la temática que se sigue en la cuenta de redes sociales. Además, sería conveniente cambiar esta imagen cada cierto tiempo.

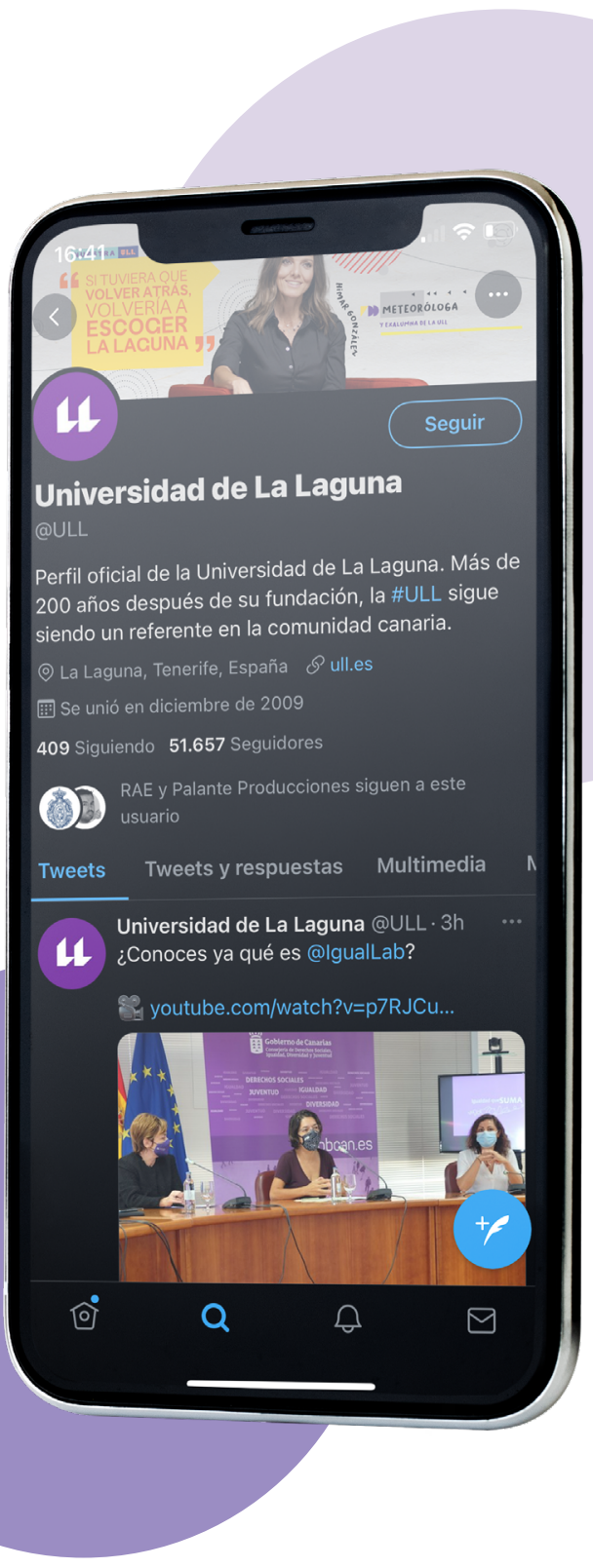

(1) 


\subsection{ELECCIÓN DEL EMAIL O MÓVIL DE RECUPERACIÓN DE CUENTA}

A pesar de que este punto puede ser algo evidente, es necesario recomendar que se haga una buena elección a la hora de elegir un email o móvil para la recuperación de la cuenta. En muchas ocasiones, serán varias las personas que gestionarán las redes sociales a lo largo del tiempo, por lo que resulta fundamental que tanto el correo como el teléfono que se configure para la recuperación sea institucional y al que tenga acceso parte o todo el servicio, departamento, centro, etc. Esto quiere decir que no se emplee como email de recuperación el correo de alguien específico para evitar así que se pierda la posibilidad de acceso si esa persona se marcha.

Pasado este trámite de validación, se procederá a la creación de la cuenta y se empezará a introducir contenido. En este punto, como ya se ha señalado, resulta fundamental que el gestor desarrolle su labor de forma activa y en consonancia con las cuentas institucionales.

De nada vale tener presencia en redes sociales para luego no dedicarle tiempo a la creación de material nuevo y original que le sea útil a los usuarios y usuarias.

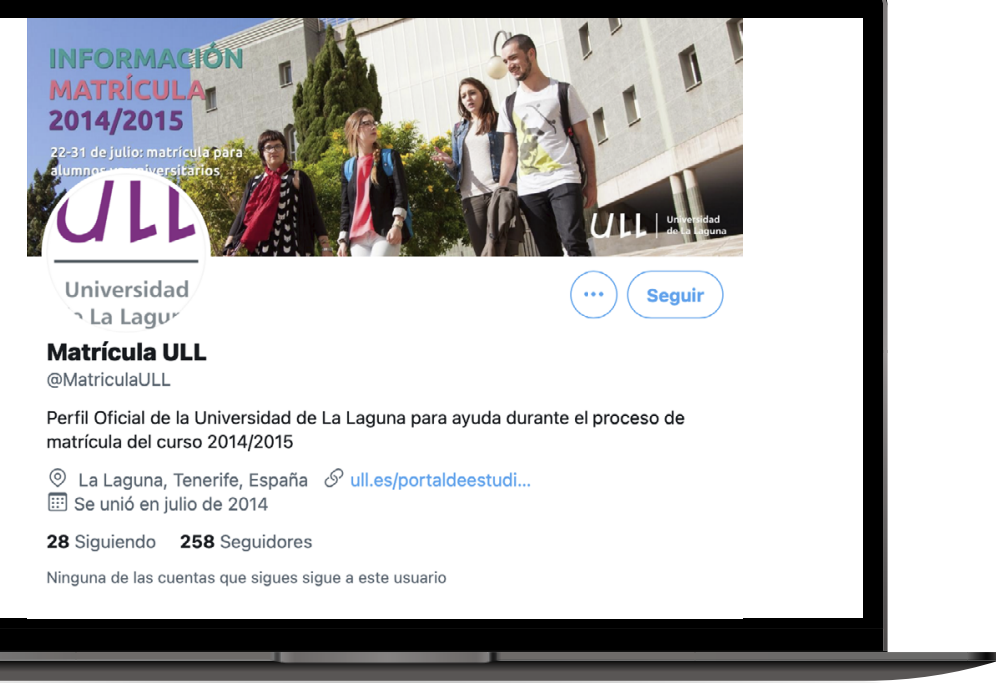

\subsection{CUENTAS INACTIVAS}

Todas las cuentas que no publiquen con regularidad y que pertenezcan al entorno de la Universidad de La Laguna han de ser revisadas y, si se estimase oportuno, cerradas. El no publicar en al menos 6 meses ya puede considerarse como cuenta inactiva. El hecho de tener cuentas sin movimiento produce confusión y falta de comunicación entre la institución académica y los usuarios, además de ofrecer una imagen poco edificante. En este sentido no solo importa el contenido que se publica sino también la falta de atención a las posibles preguntas que llegan de forma privada a las redes sociales.

Por este motivo, resulta básico realizar una buena selección de cuentas de email, e incluso número de teléfono, por si fuera necesaria llevar a cabo la recuperación de una cuenta y poder borrarla.

Si se diera el caso de que algún gestor posee la contraseña de una cuenta inactiva y la quiere cerrar, puede hacerlo directamente o comunicarlo al Gabinete de Comunicación para proceder a su eliminación. 


\subsection{MENCIONES}

2.1.1. Criterios generales para la mención

El acto de mencionar proporciona al mensaje mayor credibilidad dado que, en la mayoría de ocasiones, se está citando a la fuente original. Debido a la gran cantidad de cuentas existentes en las redes sociales y el gran parecido en sus nombres, no es improbable errar a la hora de mencionar. Por este motivo, cuando se realice una mención no debe hacerse a la ligera y será necesario fijarse bien a quién se está mencionando, así como, por supuesto, comprobar que la cuenta se trata de un perfil oficial o, al menos, pertenece a la persona, empresa, institución u organismo que se desea citar, y que está plenamente operativa.

Aunque puede cambiar dependiendo de la red social que se emplee, la acción de mencionar se realiza colocando el signo de @ delante del nombre de usuario de la cuenta que se quiere mencionar.

\subsubsection{Mención a la Universidad de La Laguna}

La Universidad de La Laguna tiene presencia en las redes sociales más destacadas de la actualidad como son Facebook, Twitter, Instagram, Youtube y Linkedin. El número de seguidores se cuenta por miles, por lo que la mejor manera para hacer crecer una cuenta vinculada a este centro académico siempre será la de apoyarse en las cuentas institucionales.

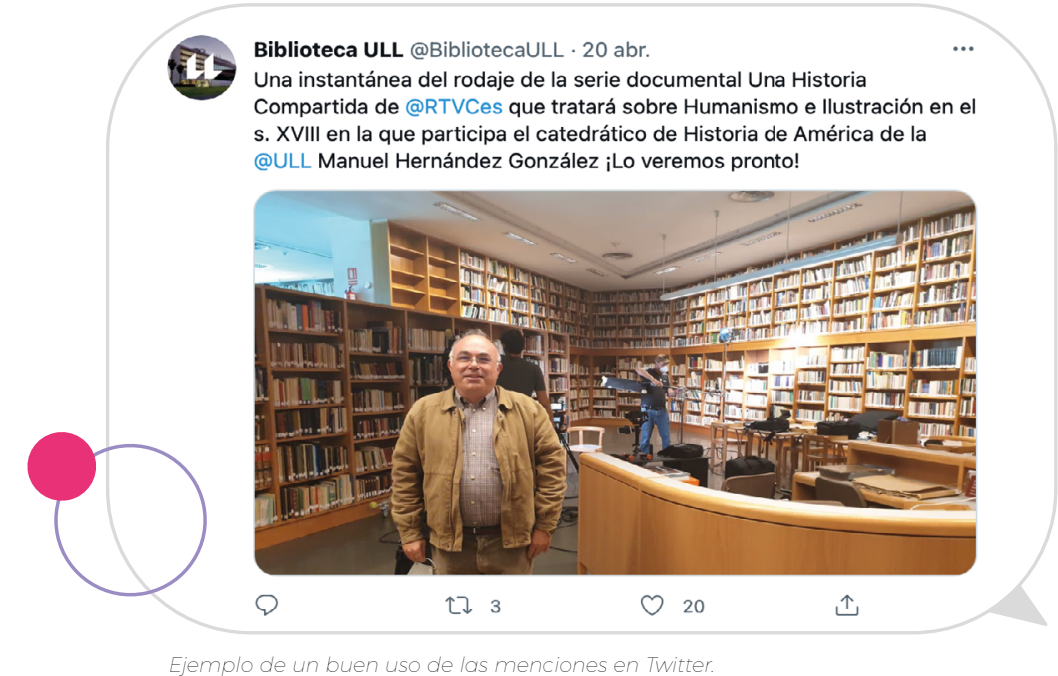

La cooperación entre las diferentes cuentas será el camino adecuado y la vía correcta para hacerlo es a través de las menciones. De esta manera el contenido específico de cuentas periféricas a la universidad podrá ser visto por el gestor de redes y posteriormente difundido entre un público mayor y más diverso. Así será sencillo que las cuentas, tanto la institucional como la periférica, crezcan.

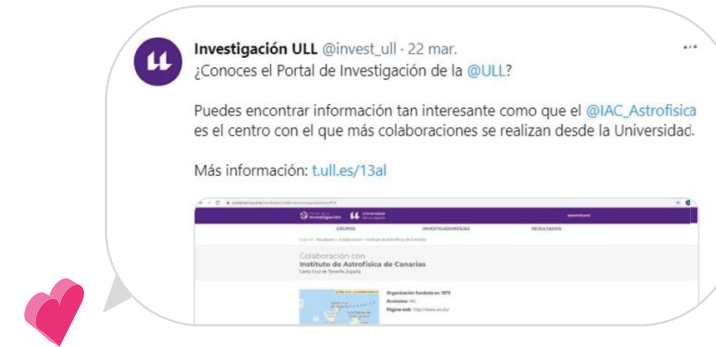




\subsection{USO DE HASHTAGS}

Las etiquetas, también llamadas hashtags, están extendidas por todas las redes sociales, aunque cada una de ellas las muestra de formas diferentes. De ahí que estos tags sean primordiales en Twitter o en Instagram y no guarden tanta relevancia en otras como Facebook pese a que se emplean de igual forma.

Si algo caracteriza estas etiquetas es que se encuentran en constante cambio y es por esta razón por la que habrá que estar siempre pendiente de la posible obsolescencia del hashtag.

En la mayoría de las ocasiones las etiquetas se crean para un periodo de tiempo determinado. El ejemplo más claro es la celebración de un evento concreto, puesto que en cuanto expire, el uso de ese hashtag, previsiblemente, ya no tendrá sentido.

Tampoco es recomendable el empleo de más de dos hashtags en una misma publicación, así como el uso de etiquetas demasiado largas, que no se entiendan, o que directamente perjudiquen la imagen de la institución. Si fuera necesario, a la hora de crear un hashtag puede ponerse en contacto con el Gabinete de Comunicación para que se valore su uso o incluso ayude a su difusión a través de las cuentas institucionales.

Además los hashtags también pueden usarse como una forma de destacar el tema central del texto o incluso como acortador (es el caso de \#ULL en vez de Universidad de La Laguna). No obstante, en ambos casos habrá que valorar si aporta algo al receptor de la información. Siempre que entorpezca la comunicación, habrá que evitar usar dichas etiquetas.

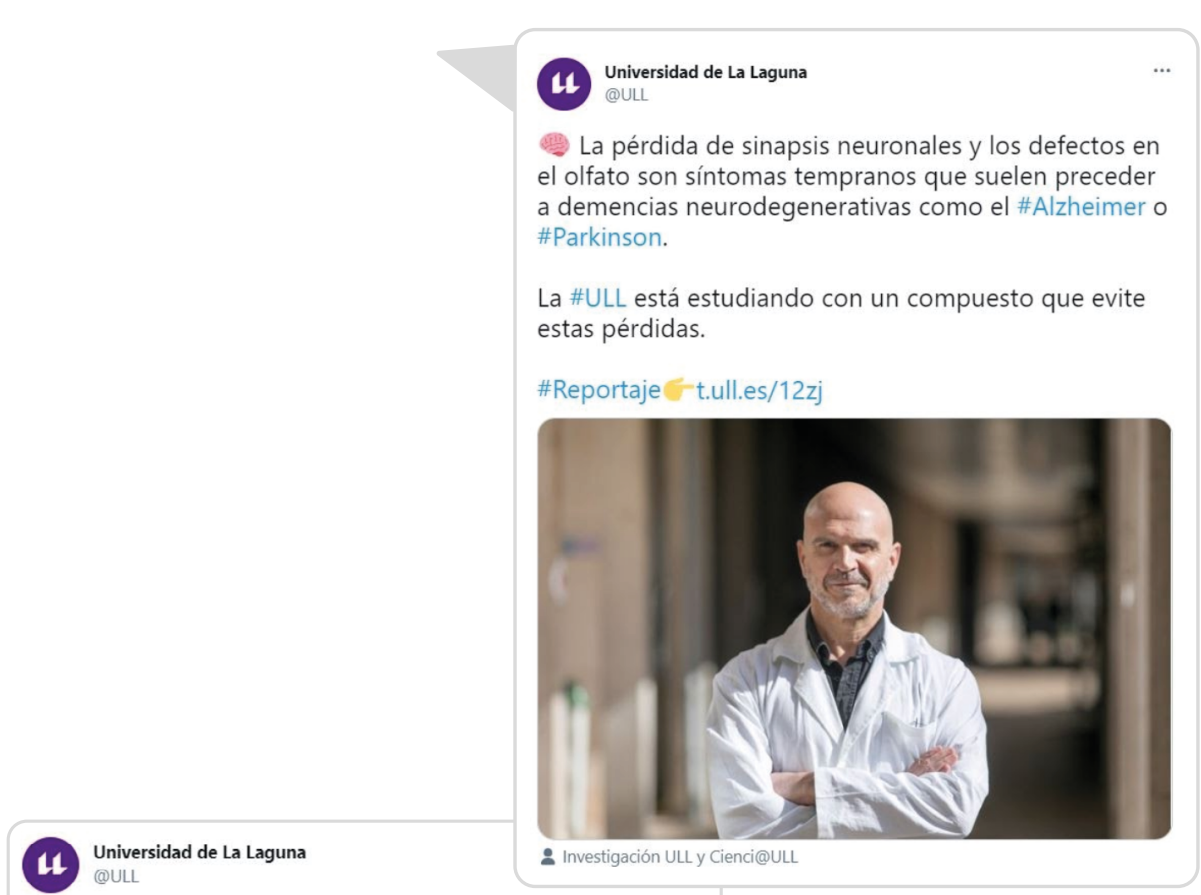

4. Mañana, viernes 5 de marzo, a partir de las 9:00 horas, el Instituto de las Mujeres de la \#ULL celebrará el acto "Mujeres por la ciencia y el conocimiento".

¿Síguelo en directo! meet.google.com/xcu-uktgdkm

- Más información $\Rightarrow$ t.ull.es/12wf

\#MujeresporlaCienciaULL

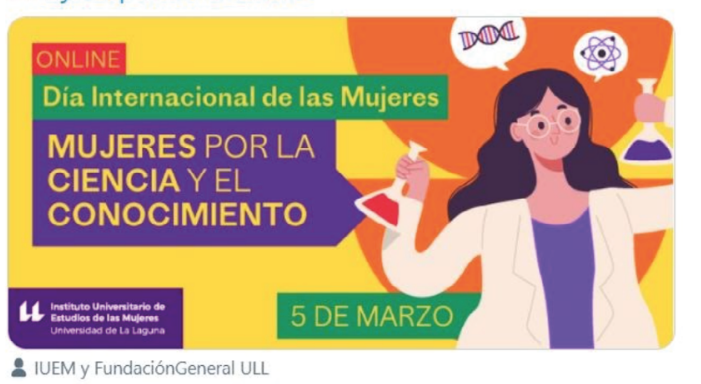




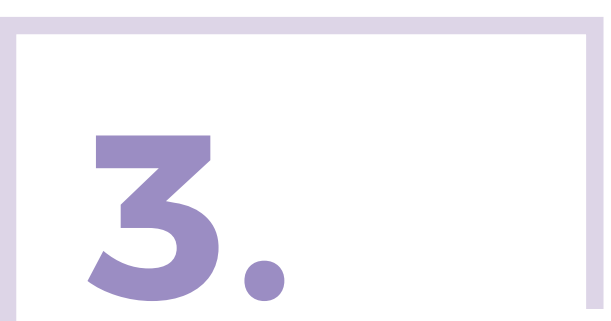

\section{Consejos y normas de estilo en la redacción en redes sociales}

Las redes sociales no solo han cambiado el canal a través del que comunicarse sino también la forma de expresarse. En el caso de las instituciones y las empresas, que también se encuentran en el mundo de los social media, con el paso del tiempo han buscado la manera de conectar con los posibles usuarios/clientes moderando y simplificando su lenguaje como una vía de comunicación más directa y cercana con sus públicos. No obstante, la Universidad de La Laguna, como organismo que aboga por el conocimiento, siempre se respaldará en el uso correcto del idioma. En las próximas líneas se darán consejos si se desea publicar en redes sociales vinculadas a esta institución académica.

\section{PRINCIPIOS GENERALES DE REDACCIÓN}

A pesar de que cada red social posee sus propias características y afecta de forma directa al mensaje que se quiere transmitir (tal vez el caso más claro es el de Twitter en el que solo permite usar 280 caracteres), siempre habrá que seguir recomendaciones tan básicas como las siguientes:

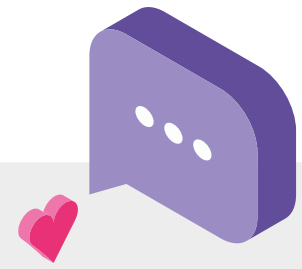

No cometer faltas de ortografía. Se puede entender alguna errata pero la postura ante estos casos debería de ser severa y ha de corregirse si se produjera. Como falta de ortografía también se considera el mal uso de los signos de puntuación (por ejemplo, no poner las exclamaciones y las interrogaciones de entrada).

El lenguaje textual puede dar pie a ambigüedades que, por la propia naturaleza de las redes sociales, pueden provocar malentendidos. Por eso es importante redactar de manera clara y directa para evitar malas interpretaciones. Evite frases muy largas, con muchas subordinaciones, y tenga muy clara la idea que se desea transmitir antes de escribir. La consigna es que el mensaje sea tan claro como conciso.

En aras de esa claridad, evite tecnicismos (en la medida de lo posible) y el lenguaje burocrático.

Tener especial cuidado con el uso de las abreviaturas y contracciones no abusar de los emoticonos: pueden ser un buen recurso expresivo para afianzar el mensaje, pero en exceso pueden restar seriedad al mensaje e incluso hacerlo más confuso.

El tono debe ser cordial y cercano, pero al mismo tiempo evitar demasiadas familiaridades y coloquialismo: tenga en cuenta que al escribir en un perfil institucional, en ese momento se está representando a la institución. Por ello, es importante cuidar el tono. 


\subsection{CONTENIDOS}

En general, el contenido de los mensajes debe circunscribirse a los asuntos propios de la entidad a la que represente el perfil de red social desde el que se escriba: si es una facultad, solamente debería centrarse en asuntos propios de la facultad; si es un servicio, sobre la actualidad del mismo, etc.

Como excepciones, se podría admitir la creación de contenidos sobre ciertos eventos y conmemoraciones que se entienda que es oportuno recordar, como por ejemplo los días internacionales sobre diferentes materias que se jalonan a lo largo del año, determinadas festividades o situaciones similares, o bien mensajes de condolencias en determinadas situaciones luctuosas.

En todo caso, conviene recordar que desde los perfiles oficiales se escribe en nombre de la entidad, por lo que quienes gestionen los perfiles habrán de abstenerse de realizar manifestaciones que expresen su opinión personal sobre cuestiones al margen de la institución (política, deporte, religión, actualidad...), ya que podría entenderse que esa es una postura oficial del centro o entidad.

Los contenidos deben ser eminentemente informativos, explicando novedades y sucesos directamente relacionados con su entidad. Puede apoyarse en enlaces a otras partes de la web o documentos, en cuyo caso aconsejamos el uso de alguno de los muchos acortadores de enlaces disponibles (acortador de la ULL).

Recuerde que algún contenido de su interés puede haber sido ya publicado por la cuenta institucional de la Universidad de La Laguna o algún otro perfil institucional. En ese caso, considere la posibilidad de retuitear o compartir ese contenido, en lugar de volver a generar una publicación sobre el mismo asunto.

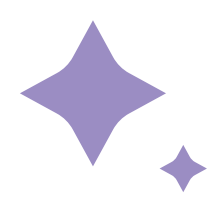

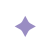

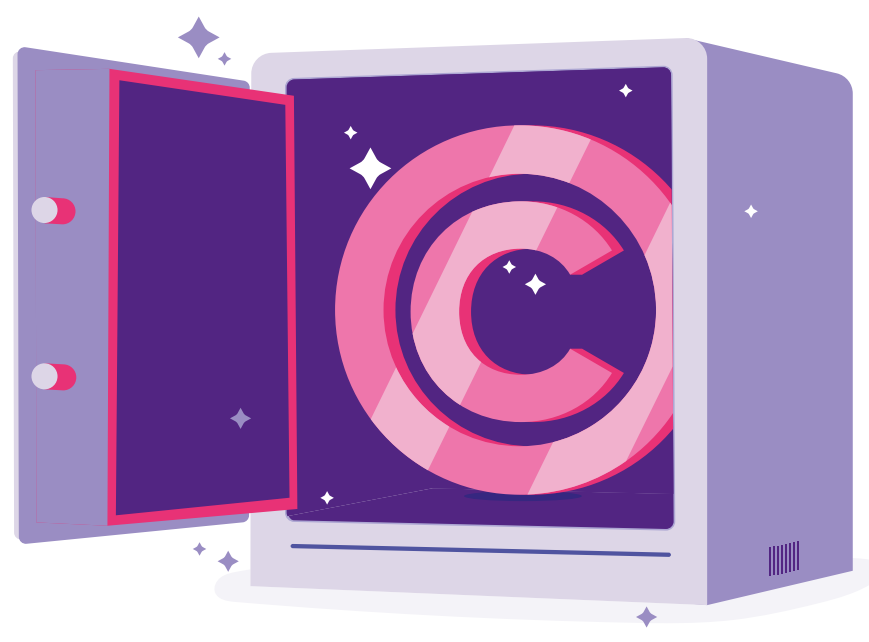

\subsubsection{Tipo de contenido gráfico (derechos de autor)}

Prácticamente todas las redes sociales premian el contenido de texto acompañado de imágenes, vídeos, GIF, etc. Justo hacemos hincapié en el uso adecuado de este contenido, dado que si se emplea, el gestor ha de tener en cuenta que no se pueden utilizar fotos o vídeos que no sean de su propiedad o que contengan derechos de autor.

Aunque un tuit, un post o una publicación pueda parecer algo insignificante, es un contenido que va a ser visto por cientos de personas y, por supuesto, si no se poseen los derechos, puede ser denunciado.

Recomendamos a todos los gestores de plataformas sociales que usen contenido gráfico propio o de bancos de imágenes sin derechos de autor. Incluso, si se viesen en la necesidad de utilizar, en algún momento determinado, una imagen de la que desconocen su autoría, es aconsejable cuál es su fuente. 


\subsection{ACTUALIZACIÓN Y MANTENIMIENTO}

La creación de contenido es clave en la gestión de las redes sociales. Sin embargo, de nada vale realizar publicaciones de forma esporádica en función de la disponibilidad que tenga el gestor. El trabajo en estas plataformas, respetando las características de cada una de ellas, ha de ser constante. Es más, se podría decir que para ser efectivo los perfiles tendrían que ser actualizados a diario, a poder ser con contenido propio.

En cuanto al mantenimiento, el gestor tendrá que tener en cuenta también la actualización de la información del perfil, la imagen de perfil, etc. Además, se encargará de las respuestas a las preguntas que llegarán a las redes. Es importante dedicar tiempo a contestar a los usuarios, dado que estas plataformas no son un canal unidireccional sino bidireccional. Es más, el no responder a las posibles dudas puede generar comentarios negativos, e incluso dar pie al inicio de una crisis que puede afectar a la imagen de la institución.

Si no fuera posible atender adecuadamente las cuentas de redes sociales vinculadas a la Universidad de La Laguna, lo más recomendable es que se ponga en contacto con el Gabinete de Comunicación (web@ull.es) para que le asesoren y busquen una alternativa.

\subsection{GESTIÓN DE COMENTARIOS Y MENSAJES DIRECTOS}

Tal y como se señala en el punto anterior, las redes sociales son un canal bidireccional, que se usa para la publicación de contenido pero que también recibe feedback de las personas que las siguen.

Los usuarios de las redes sociales, más aún en la universidad, emplean estas plataformas para enviar sus dudas, preguntas o comentarios, entendiendo a la institución como una entidad única. Además, reclaman una respuesta rápida y eficiente sin importar de dónde parta la información, ya sea de una secretaría de una facultad, un servicio, un vicerrectorado, etc. Esto quiere decir que es probable que los gestores de las redes se topen con cuestiones que ni ellos mismos pueden responder, dado que no tiene ni por qué saberlo, pero aun así, lo que hay que hacer es buscar la respuesta correcta, dirigiéndose a la fuente de la información, y aportarla lo antes posible.

Estas contestaciones no pueden verse como una acción laxa. Es más debe erigirse como uno de los puntos fuertes en la gestión de las redes, puesto que el ignorar las dudas de los usuarios puede convertirse en un problema de reputación para la institución. Por lo tanto, mantener conversaciones y ser eficaces en las respuestas y en el servicio que se presta resulta clave para nuestra reputación digital.

Contestar a los usuarios no puede ser una actividad secundaria, pero con esta afirmación tampoco estamos haciendo un llamamiento a responder a todo ni a entrar en cualquier debate. En numerosas ocasiones los seguidores de una cuenta expresarán su parecer acerca de determinados temas, sin más. Tras analizar el caso, si procede y se trata de una pregunta (ya sea en público o en privado) o incluso de una afirmación incorrecta, siempre es conveniente responder, dado que esto otorgará trasparencia a la cuenta, pero eso no significa que debamos dar pie a polémicas.

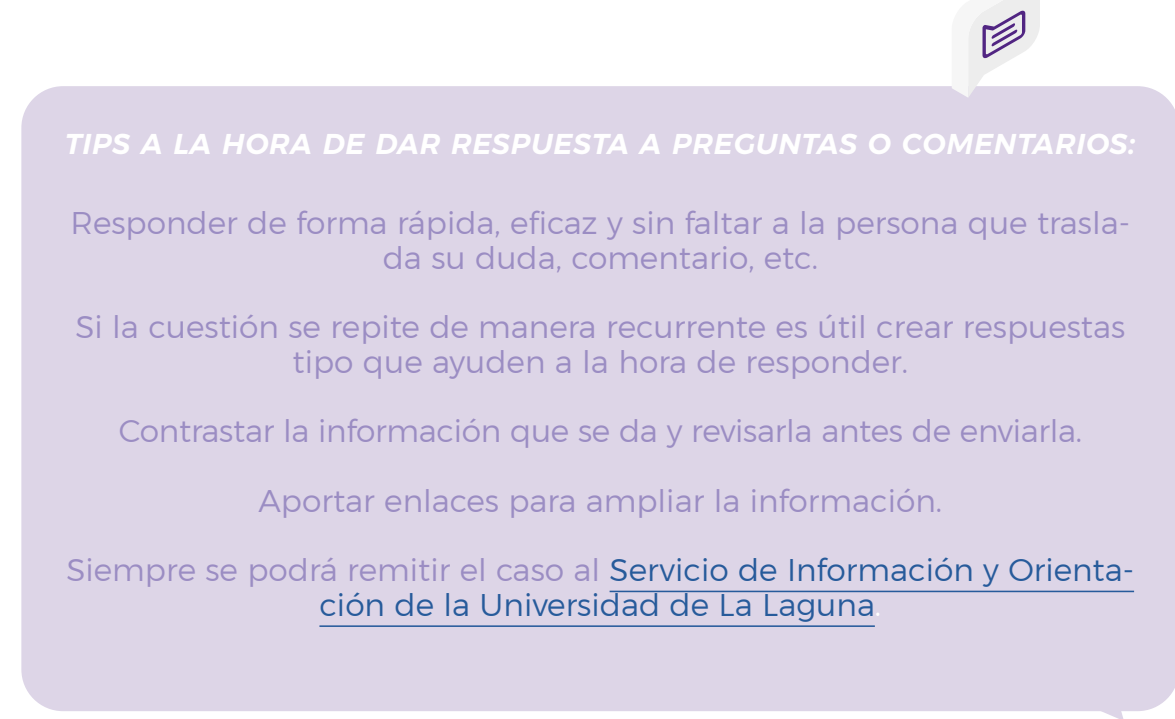


La mayoría de las redes sociales en la actualidad disponen de la posibilidad de entablar conversaciones con los seguidores de forma pública (que puede ser leída por todo el que lo desee a través de comentarios) y privada (chat). Partiendo de la base de que disponemos de estas dos formas de responder podemos establecer las siguientes cuestiones a tener en cuenta:

- Si la pregunta se realiza en público, lo normal es que se responda en abierto. No obstante, habrá casos en los que es mejor redirigir la conversación al chat privado debido a que dicha contestación sea demasiado larga (sobre todo si llega a Twitter), a que en la respuesta tengan que aportarse datos personales del usuario o que contenga información que solo atañe a la persona que pregunta.

- Las cuestiones que lleguen a través del chat han de ser respondidas en privado.

- En el caso de que se produzca una pregunta de forma recurrente en privado, será conveniente analizarla y realizar una publicación en abierto que zanje las dudas de los usuarios, en vez de estar respondiendo de forma individual, lo que nos podría llevar mucho más tiempo.

\subsection{GESTIÓN DE CRISIS}

En un momento de máxima exposición pública, y de enormes exigencias en transparencia y comportamiento excelente, cualquier marca ha de estar muy atenta a todo conato de crisis en el contexto digital. Las redes sociales pueden llegar a ser una magnífica herramienta para detectar las primeras percepciones de lo que posteriormente puede degenerar en una crisis. Por este motivo, resulta básico gestionar cualquier incidencia que se produzca en el ámbito digital a la mayor brevedad posible en cualquier plataforma. Tanto es así que una mala comunicación o, incluso, una omisión de respuesta, puede perjudicar a la institución gravemente en la parte online $u$ offline.

Ante una crisis lo primero que se debe hacer es analizar dónde se ha generado. Muchas críticas suelen llegar de usuarios individuales, a los cuales en general se podrá contestar y resolver el problema sin mayor dificultad. Si por el contrario la crítica proviene de medios de comunicación e incluso desde otras cuentas que poseen un gran número de seguidores, la gestión ha de ser mucho más comedida y meditada, puesto que lo que publiquemos en redes sociales será público y por tanto criticado también.

\section{Algunos puntos a tener en cuenta:}

Contestar sin faltar al respeto. Siempre hay que responder de buena manera a todos los usuarios.

- No dar la opinión personal en ningún momento. Representa a una institución.

Evitar discutir. Lo mejor es una respuesta concisa y si necesita más información puede redirigirlo a través de un enlace.

- No eliminar comentarios, pese a que sean negativos (salvo ocasiones excepcionales). Esta acción resta credibilidad.

- No mentir ni alterar la realidad de los hechos. Reconocer lo que ha sucedido y despejar dudas.

- Cuando hay que disculparse por una gestión inadecuada es mejor hacerlo a tiempo. Por lo general, los usuarios prefieren la sinceridad y la aclaración inmediata de lo sucedido, reconociendo los errores si es que los hubo.

- Ofrecer alternativas de resolución de la crisis. Qué vamos a hacer para solventar lo sucedido, qué medidas se van a tomar en cuenta.

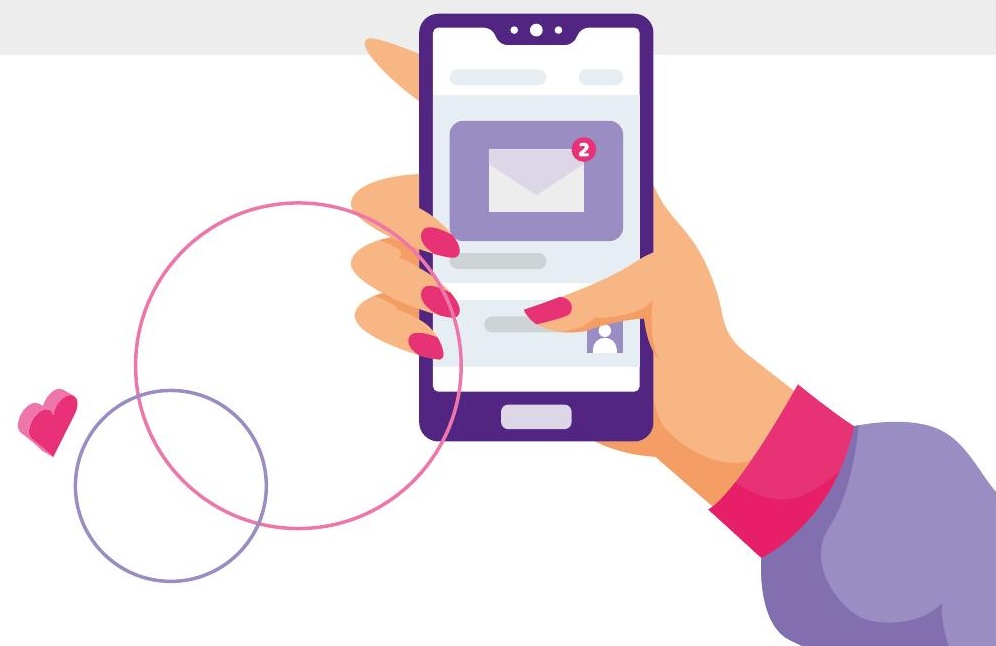



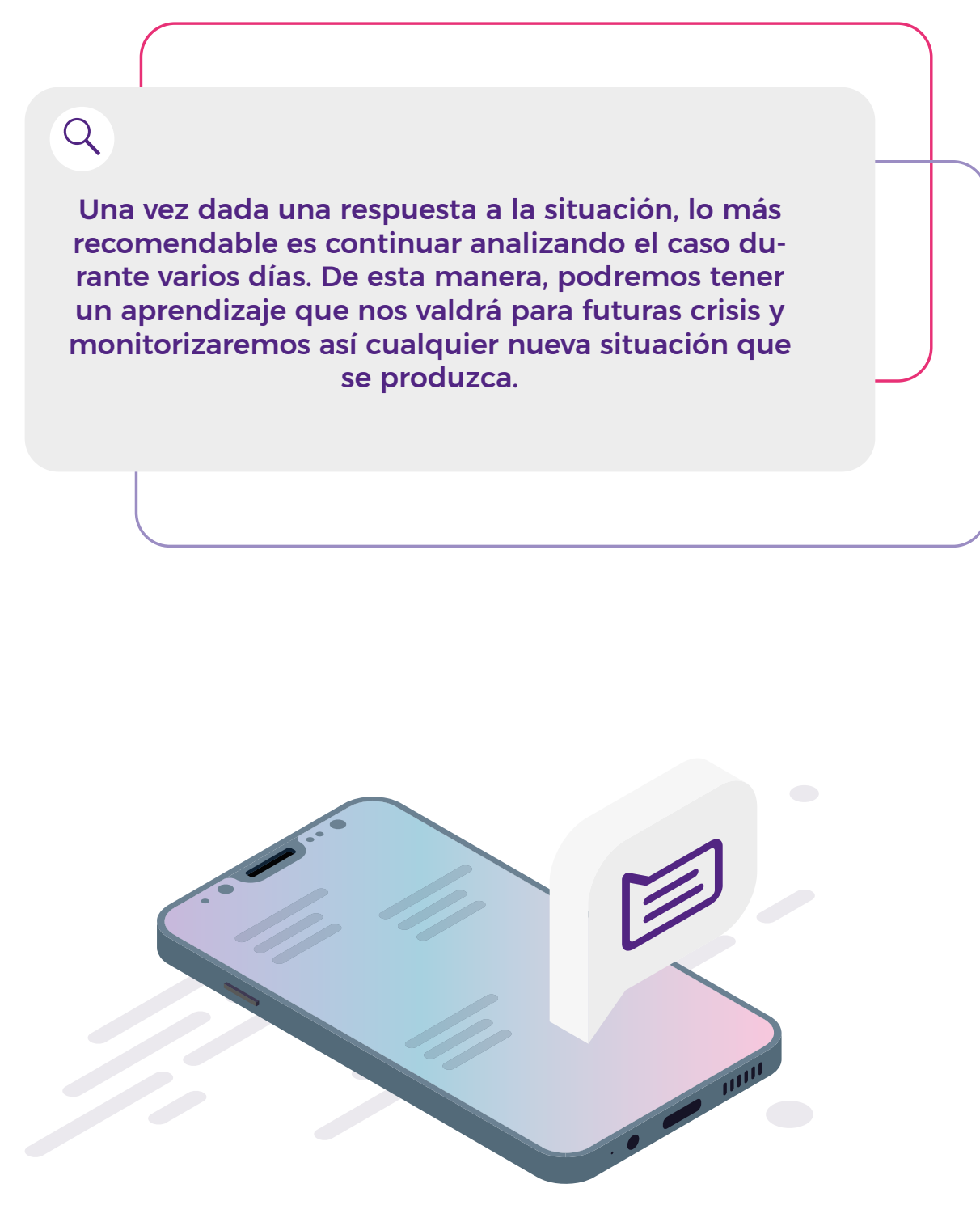

En redes sociales no se deben subestimar las posibles crisis, que pueden coger una dimensión inusitada en poco tiempo. Aunque es cierto que se puede no responder, la vía de quedarnos callados puede afectarnos tanto o más que contestar de forma incorrecta. Por este motivo, es fundamental evaluar la crisis, dónde se ha originado, por qué, dar una respuesta comprensible (si es oportuno) y analizar cómo se podría evitar en el futuro.

En cualquier caso el Gabinete de Comunicación puede asesorar ante cualquier crisis en el ámbito digital (web@ull.es).

\subsection{Análisis estadístico}

La gestión de las redes sociales no solo se limita a la publicación de contenido y a crear conversación con los públicos. Uno de los puntos fundamentales en este trabajo radica en el análisis posterior de lo que se hace. Para ello, se ha de profundizar en las métricas de cada plataforma y hacer un repaso de nuestro crecimiento o decrecimiento, alcance, cuáles han sido los posts con mayor interacción, entre otros parámetros.

Esta labor sería óptima si se llevase a cabo al menos una vez al mes y se recogiesen datos de cada una de las redes sociales en las que se tiene presencia. Desarrollando este trabajo con frecuencia se puede entender mejor el público al que nos dirigimos, sus intereses y contenidos preferentes. Contacte con el Gabinete de Comunicación (web@ull.es) para buscar asesoramiento sobre este extremo. 


\section{FACEBOOK}

Facebook es la red social que posee el mayor número de usuarios activos al mes con más de 2.400 millones. En la actualidad, según el último estudio del Interactive Advertising Bureau (IAB) publicado en junio de 2020, esta red se erige como la segunda más usada en España, solo superada por Whatsapp. Teniendo en cuenta estos datos, no resulta complejo valorar la importancia que tiene la presencia de la institución en este canal, que sirve tanto para la difusión del contenido propio, como para la interacción con sus públicos, o incluso para establecer diálogos con los usuarios a los que les interesa este centro académico.

A pesar de que no es la red social con más usuarios, la Universidad de La Laguna posee una comunidad de más de 36.000 seguidores y Facebook, actualmente, se erige como uno de los social media principales en su estrategia de comunicación.

A la hora de estar presente en Facebook, lo recomendable siempre es tener una página de empresa. Aunque sea necesario acceder a través de un perfil personal, este no puede ser utilizado al realizar comunicaciones oficiales en nombre de esta institución académica.

\section{Denominación de cuentas en Facebook}

El nombre de la página de Facebook será la carta de presentación para los usuarios y usuarias, así que habrá que buscar un denominador que se ajuste lo máximo posible al nombre del vicerrectorado, servicio, departamento, etc.

\section{Imagen de perfil y de portada}

Al personalizar la cuenta en Facebook se debe incluir una imagen/fotografía tanto en el perfil y en la portada. En el primero de los casos, sería conveniente usar el logo oficial de la Universidad de La Laguna o si lo tuviese el logo específico del vicerrectorado, servicio, departamento, etc.

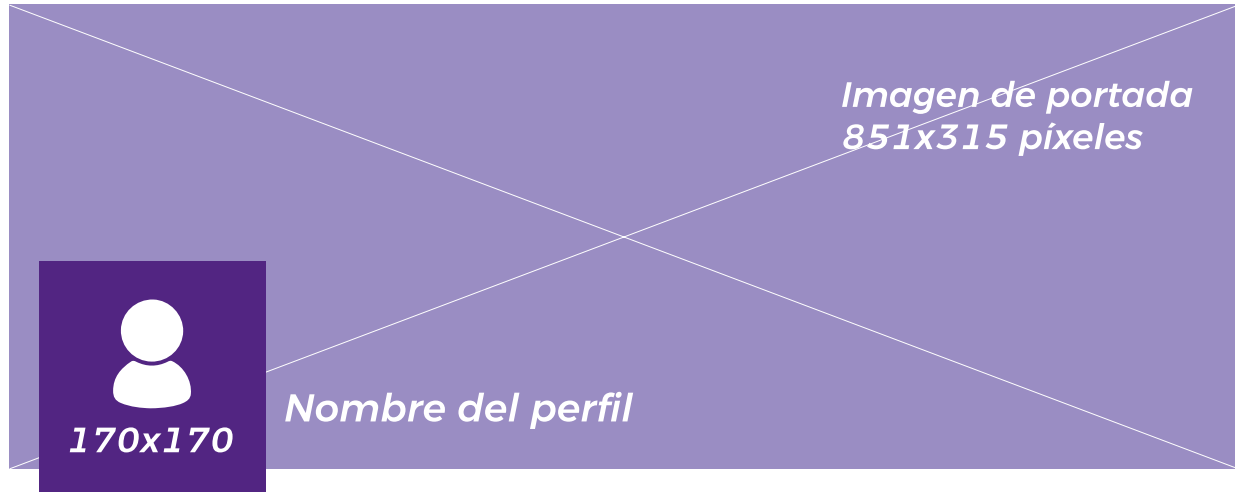

\section{Características imagen de perfil:}

- 170x170 píxeles

$100 \mathrm{~Kb}$ de peso

- Formato JPC o PNC

La portada, al igual que el perfil, deben representar a la institución. Aunque en la portada cabe más "creatividad"

deberá utilizarse una imagen/fotografía que represente a

la institución.

Las características de esta imagen son:

$851 \times 315$ píxeles 


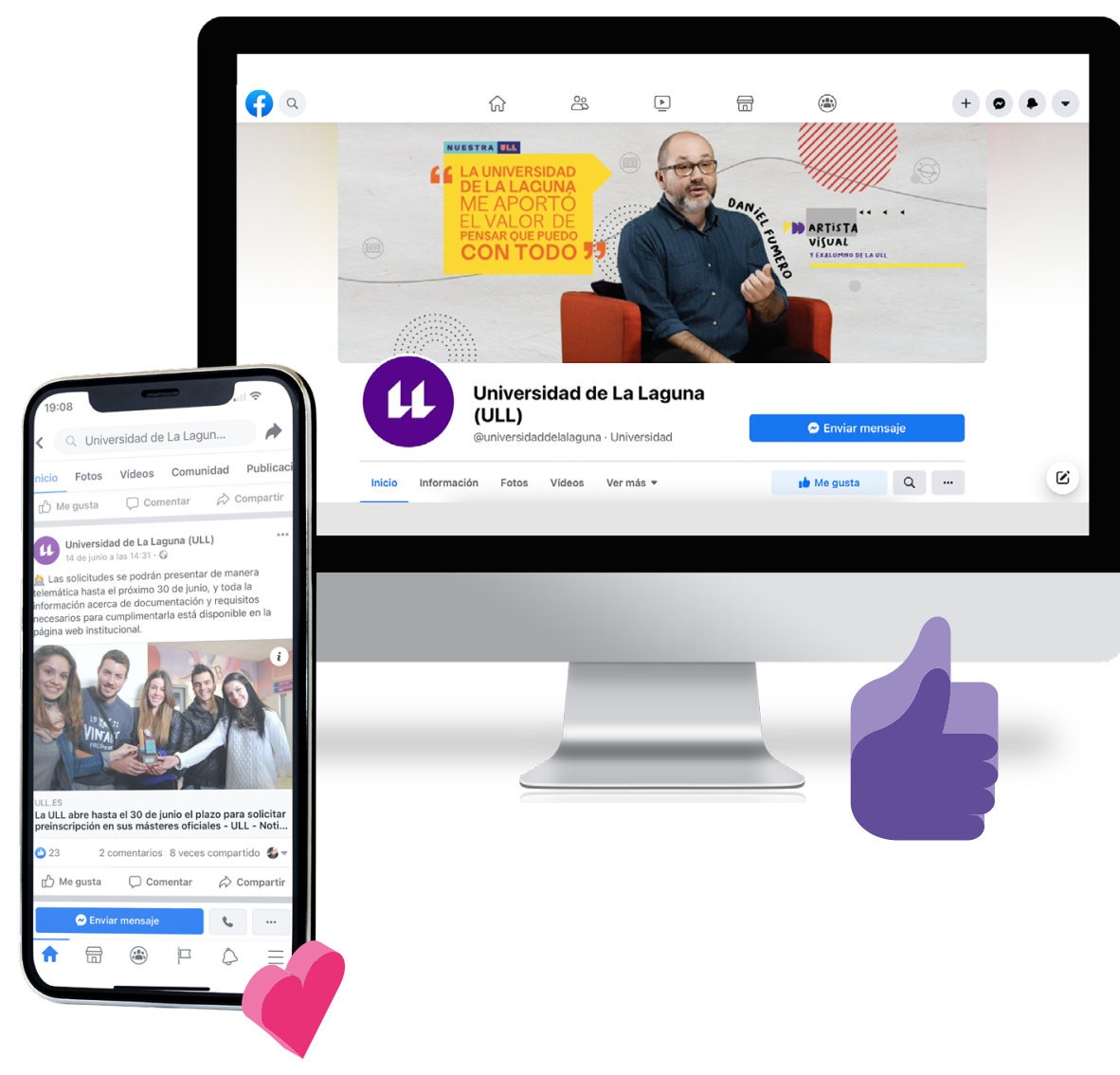

\section{CONTENIDO}

Como se lleva haciendo hincapié en todo este manual, uno de los puntos clave en una buena gestión de redes sociales será el contenido que se aporte al usuario. Por este motivo, habrá que ser consciente de que se publica en nombre de la institución en todo momento.

Lo más recomendable es realizar publicaciones de forma recurrente (1 al día es aconsejable) pero dependerá siempre de la cantidad y calidad del contenido. Además, la creación de posts propios, más que compartirlos de otras páginas, es lo más conveniente, dado que le aporta valor a la cuenta.

Pese a que Facebook está en constante cambio, el tipo de contenido que más relevancia posee actualmente es el vídeo, por lo que transmitir a través de este formato hará que se llegue a un mayor número de usuarios. No obstante, la publicación de fotos o enlaces suele ser lo más recurrente en la gestión de este social media, que también posee Instagram y Whastapp, lo que le da cierta libertad a la hora de innovar y premiar el tipo de contenido que desee.

Las stories pueden llegar a ser una buena herramienta a la hora de publicar contenido aunque será preciso ajustarse a los tamaños verticales que nos ofrece la plataforma.

Facebook también permite realizar directos aunque existen diversas herramientas para llevar a cabo esta acción y que son más usadas.

Aunque esta red social no limita el número de caracteres, hay que saber llegar al usuario y es muy importante sintetizar el mensaje. Siempre cabrá la posibilidad de añadir un enlace en el que se amplíe la información, que podrá ser acortado con el acortador de URLs de la ULL o con otros conocidos como bit.ly, etc. Por lo tanto, los posts que se realicen han de ser cortos, entendibles y concisos. El gestor o gestora también podrá apoyarse en el uso de iconos o hashtags, pero siempre que no entorpezcan la lectura. 


\section{TW I T TER}

Esta red social se diferencia del resto por su naturaleza eminentemente informativa y, sobre todo, por su limitación de caracteres a la hora de publicar contenido (280 por cada tuit). La Universidad de La Laguna tiene presencia en este canal desde el año 2009 y en poco más de una década de actividad cuenta con unos 52.000 seguidores. Esta comunidad se muestra activa diariamente y ha propiciado que Twitter se convirtiese en una red social fundamental dentro de la estrategia comunicativa de este centro académico.

\section{Denominación de cuentas en Twitter}

Como se ha señalado anteriormente con Facebook, el nombre de la cuenta de Twitter será la carta de presentación para los usuarios, así que habrá que buscar un denominador que se ajuste lo máximo posible al nombre del vicerrectorado, servicio, departamento, etc. En este caso, esta red social permitirá 50 caracteres en el nombre de perfil y 15 en el nombre de usuario.

\section{Imagen de perfil y de portada}

Esta plataforma también ofrece la posibilidad de usar una imagen de perfil y otra de portada. En el primero de los casos, lo más conveniente es usar el logo de la Universidad de La Laguna para que los usuarios puedan reconocer rápidamente a qué institución pertenece.

La portada, al igual que el perfil, deben representar a la institución. Aunque en la portada cabe más "creatividad" deberá utilizarse una imagen / fotografía que represente a la institución.

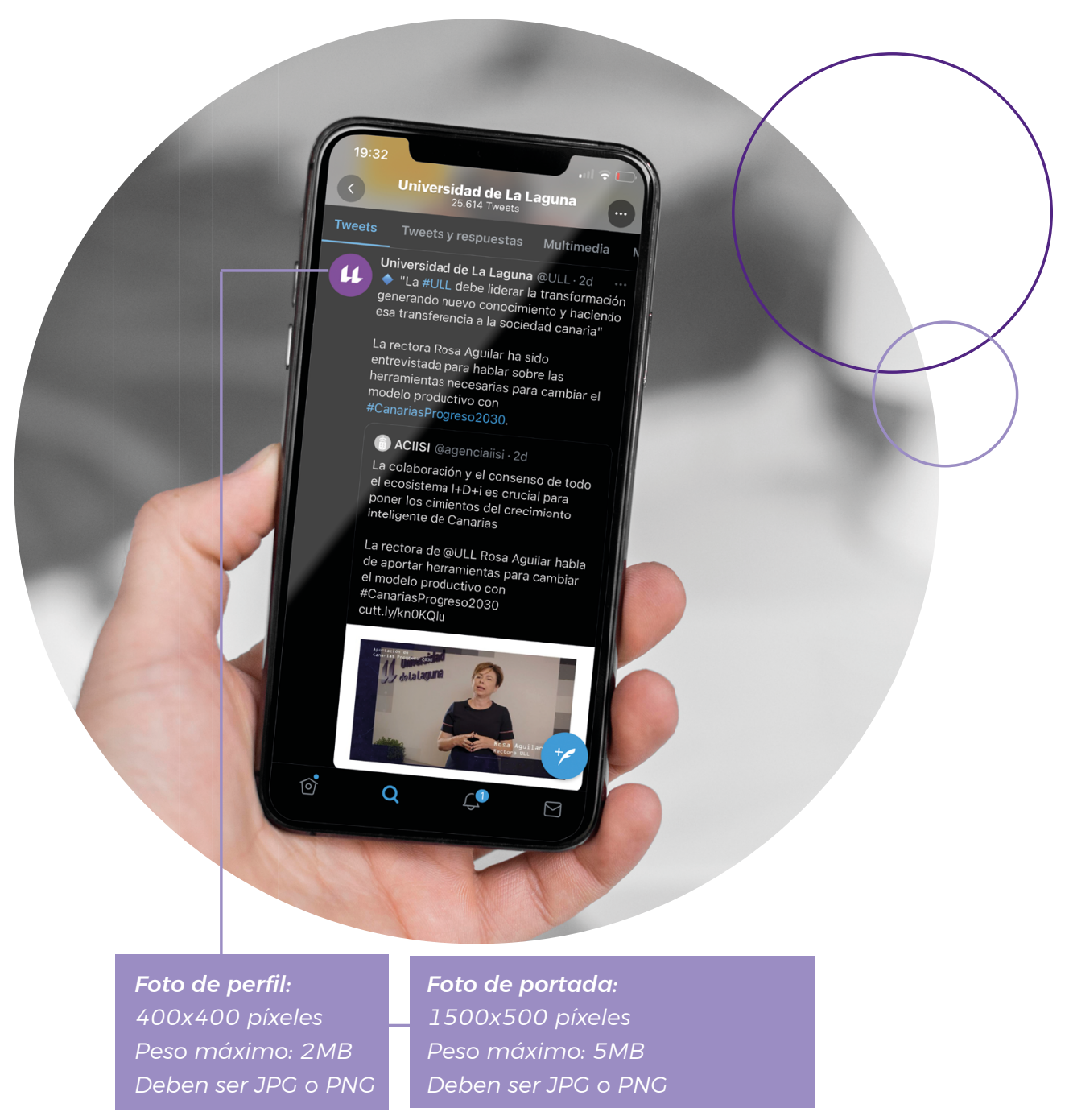




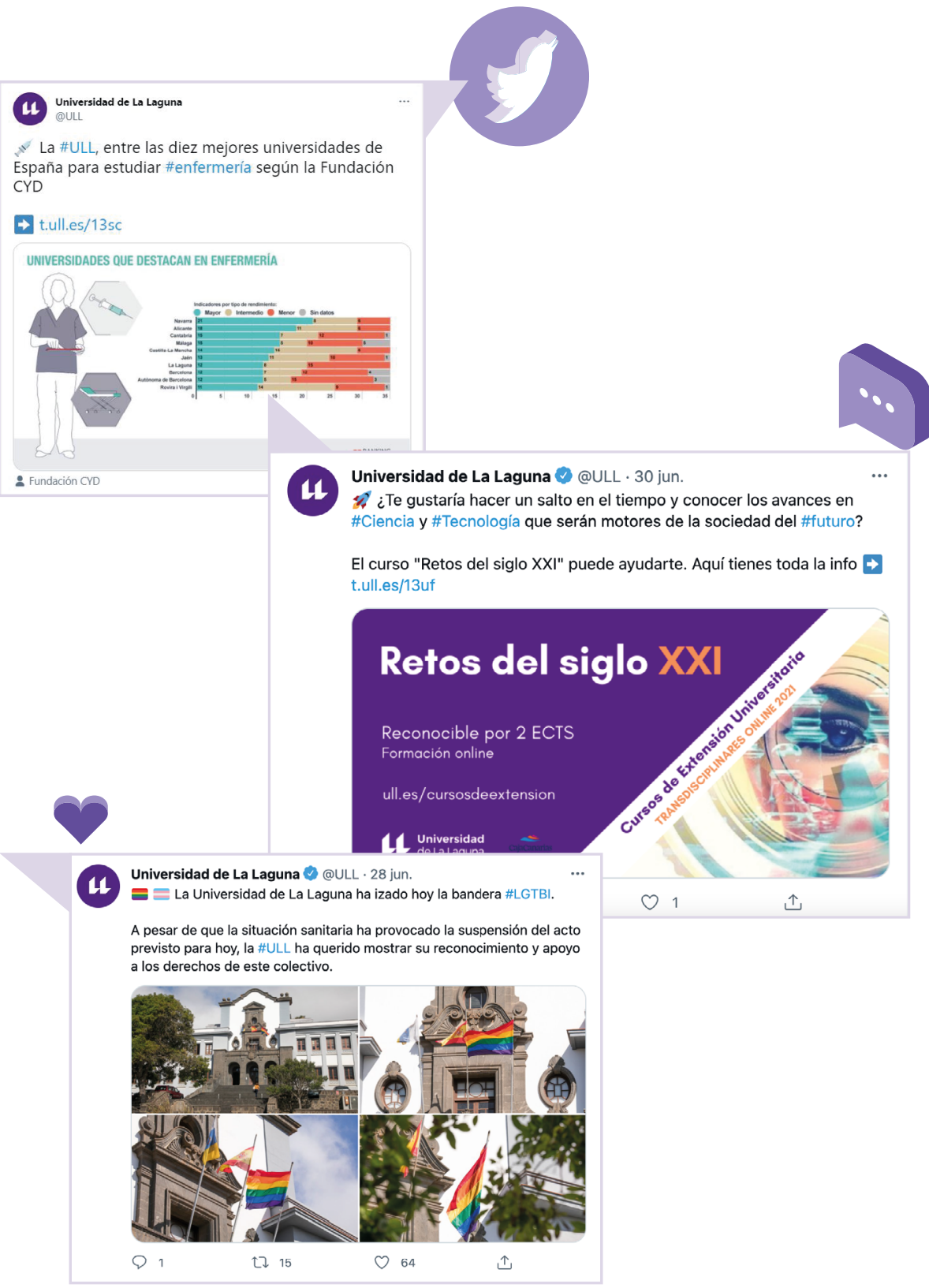

\section{CONTENIDO}

Como es evidente el contenido en esta red social va a estar condicionado por el espacio que tenemos, por lo que será imprescindible ser conciso a la hora de realizar publicaciones. No obstante, el juego que nos da Twitter al publicar es relativamente amplio y si fuera necesario llevar a cabo un post largo el gestor se puede apoyar en los hilos (cadena de tuits). Aun así, este recurso no debería ser algo recurrente.

Aunque sea una plataforma de microblogging resulta fundamental el uso de fotografías o de vídeos en la publicación de tuits. Su empleo hace que los tuits sean más atractivos para el usuario que nos sique. Además, las etiquetas o hashtags cobran especial relevancia en Twitter puesto que es la forma en la que los "tuiteros" conocen fácilmente de lo que se está hablando. Un ejemplo muy común se produce en los días mundiales de efemérides que se convierten en tendencia (Trending topic) puesto que muchos usuarios están mencionando ese tema en concreto en un determinado periodo de tiempo. Las menciones se erigen como otro punto clave en Twitter y es que de esta forma se puede etiquetar a la fuente principal.

Aunque el contenido puede variar, el tipo de tuit idóneo vendría a ser el que está compuesto por texto, fotografía o vídeo y un enlace para ampliar la información. En él podría incluirse un hashtag así como una mención. Habría que evitar los tuits que solo lleven texto o que solo se compongan por una foto, etc.

La opción de retuit es básica y sencilla a la hora de compartir contenido. Siempre que sea la fuente principal que genera el contenido e incumba a la institución se puede compartir retuiteando directamente. No obstante, es recomendable elegir la opción de "citar tweet" si queremos que nuestra marca esté presente. 


\section{I N S TA R A M}

La red social de las fotografías ha ido cambiando a lo largo del tiempo. Tanto es así que comenzó siendo una plataforma en la que las imágenes eran su principal contenido y ahora disponen de vídeos, stories, IGTV, directos, etc. Aunque esto no es un caso que solo se esté produciendo en Instagram, dado que las otras redes sociales también van ampliando su campo de acción y su forma de llegar al público, sí que es la red que más novedades ha presentado en un corto periodo de tiempo.

Esta estrategia le ha servido para hacer frente a su competencia y seguir estando presente entre sus usuarios eminentemente jóvenes. Justo este punto, su público juvenil, es el apartado más interesante a la hora de tener presencia en esta plataforma. Pese a que la comunidad de la Universidad de La Laguna en este social media no es tan amplia como en Facebook o Twitter, es una red que crece prácticamente a diario y que cada vez adquiere más relevancia dentro de la estrategia comunicacional.

\section{Denominación de cuentas en Instagram}

Al igual que sucede con Facebook o Twitter, la denominación de las cuentas en Instagram serán la carta de presentación para los usuarios. Por este motivo, se ha de ajustar lo máximo posible al nombre del vicerrectorado, servicio, facultad, etc. del que se crea la cuenta. La biografía del perfil tiene un máximo de 150 caracteres.

\section{Imagen de perfil}

Esta plataforma no posee portada por lo que solo habrá que buscar una imagen de perfil. En este sentido, lo más conveniente es usar el logo de la Universidad de La Laguna para que los usuarios puedan reconocer rápidamente a qué institución pertenece.

Las características de esta imagen son:

180x180 píxeles (medida recomendada) / JPC

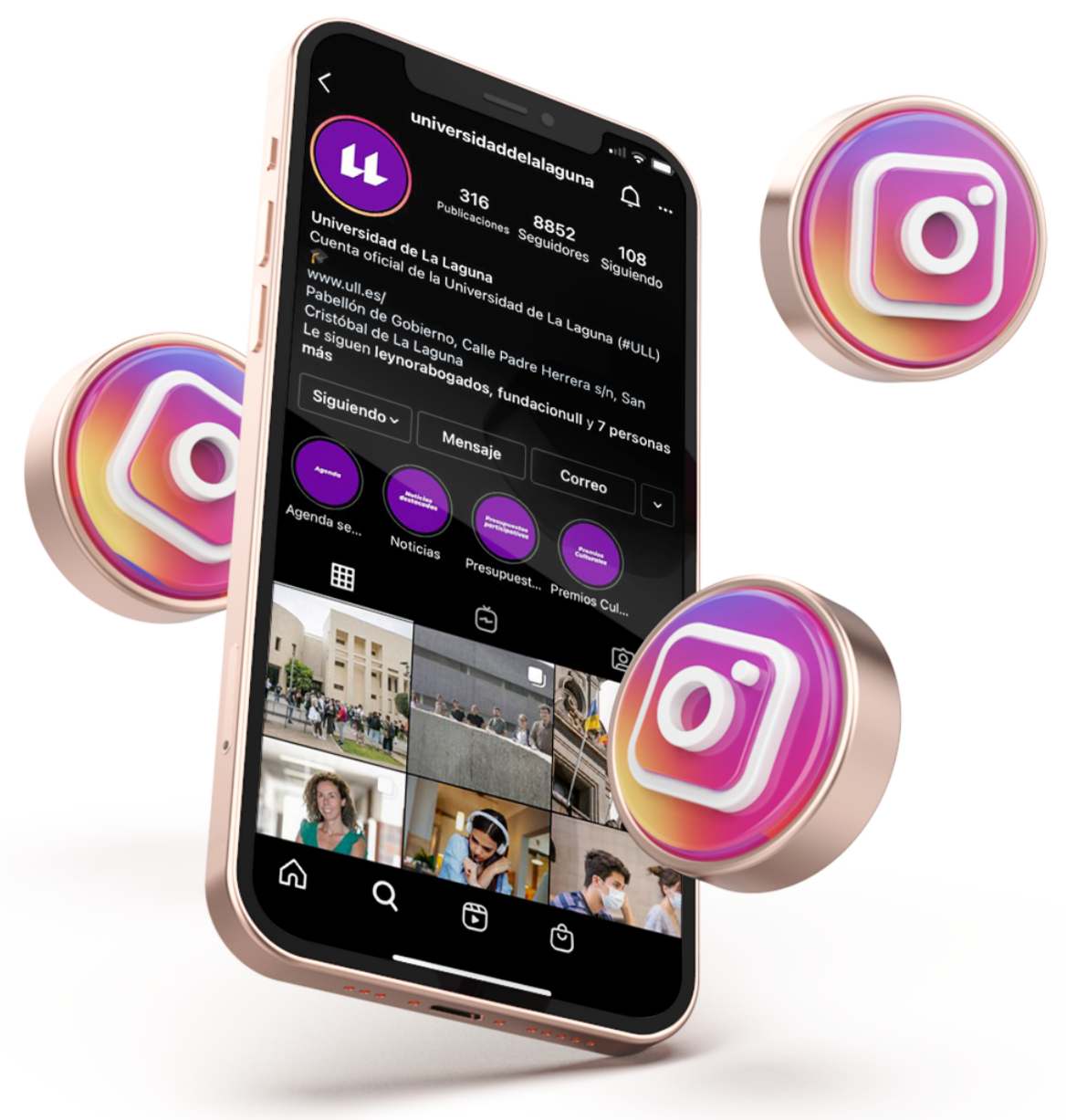




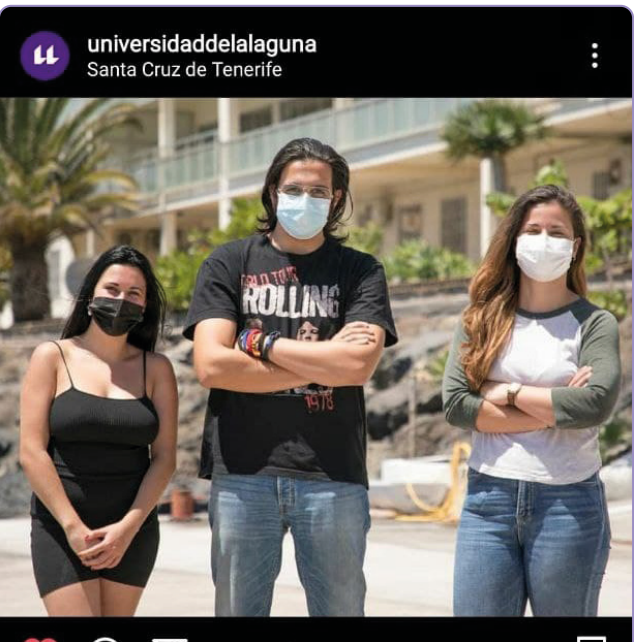

○ $\nabla$ $\cdots \ldots$

ఐ

168 Me gusta

universidaddelalaguna $\underline{\underline{\Delta}}$ La Sección de Náutica de la

\#ULL es el bastión sagrado para los que llevan en vena la

vocación marinera y los que decidieron ligar su vida al mar.

¡Ahora se rearma con nuevas especialidades y mejoras en

sus sistemas e instalaciones!

\#Reportaje c https://t.ull.es/13nw

\#UniversidaddeLaLaguna \#Náutica \#mar

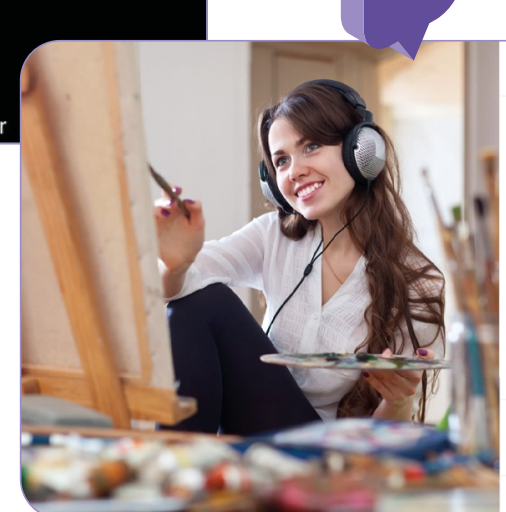

(ans

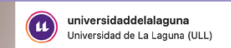

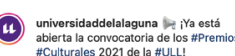

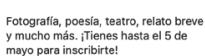

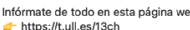

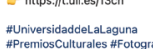

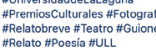

$O \bigcirc \nabla$

\section{CONTENIDO}

Como se mencionó en la introducción, esta red social centra su contenido en la fotografía. Sin embargo, en la actualidad posee diversas formas de compartir, ya sea a través de posts convencionales, historias, vídeos cortos, vídeos largos en IGTV o directos. A pesar de la variedad de opciones, lo más común y recomendable es el uso de imágenes de buena calidad unidas a un texto explicativo en la descripción, así como el empleo de algunas etiquetas.

La medida de los posts puede ser determinante a la hora de llegar más o menos al público. Aunque lo normal es que se realicen publicaciones con fotografías o vídeos en tamaño cuadrado (1080x1080 píxeles), la tendencia de esta red social es premiar el contenido en formato vertical (1080x1350 píxeles), dado que impacta más al usuario receptor de la información.

Las instituciones académicas tienen tendencia a publicar mucho contenido gráfico, por ejemplo cartelería, debido a su alta capacidad para celebrar diversos eventos. Sin embargo, recomendamos que este tipo de posts no inunden el muro de la cuenta de Instagram y que se traslade a las stories, que poseen un tiempo finito en el que puede ser visualizado (se elimina a las 24 horas). Siguiendo esta premisa, es adecuado que en las fotografías que se publiquen aparezcan personas, puesto que está demostrado que genera mayor compromiso entre la marca y los usuarios.

La posibilidad de compartir en Instagram está muy limitada, a no ser que se empleen herramientas externas, por lo que el contenido ha de ser principalmente propio. Por este motivo, a la hora de poner en marcha una cuenta en esta red habrá que sopesar si es factible la posibilidad de disponer de fotografías o vídeos de forma diaria. Si no fuera posible, lo mejor sería descartar la idea.

El funcionamiento de esta plataforma también se basa en el uso de hashtags, aunque no debe ser una acción llevada a cabo a la ligera. A pesar de que treinta es el máximo de etiquetas que se puede usar en cada publicación, lo recomendable es usar menos de diez y todas han de estar vinculadas con el contenido del post que se haya realizado. 


\section{YOUTUBE}

Esta red social se centra en compartir contenido audiovisual. La Universidad de La Laguna pretende crecer en este tipo de publicaciones. La comunidad que actualmente posee la institución en esta plataforma no es extensa, aunque bien es cierto que se tiene una estrategia clara de agrupación de canales. A pesar de que en Youtube existen diversos canales vinculados a la universidad que se gestionan de forma externa, la intención es reagrupar el máximo posible de ellos en la cuenta institucional, distribuyéndolos en listas de reproducción. Contacte con el Gabinete de Comunicación (web@ull.es) para cualquier duda sobre este punto.

\section{Denominación de canal de Youtube}

Tal y como sucede con el nombre de usuario de las otras redes sociales, el título del canal en Youtube ha de describir rápida y fácilmente qué servicio, facultad, departamento, etc. que representa. Aun así, hacemos hincapié en seguir la estrategia marcada por la cuenta institucional y antes de comenzar con un canal nuevo, contacte con el Gabinete de Comunicación.

\section{Imagen de perfil y de portada}

Esta plataforma permite el uso de imagen de perfil ( $100 \times 100$ píxeles), en el que es recomendable el empleo del logotipo de la Universidad de La Laguna, y de portada (2560x 1440 píxeles), en el que sería conveniente utilizar una imagen relacionada con la temática del canal.
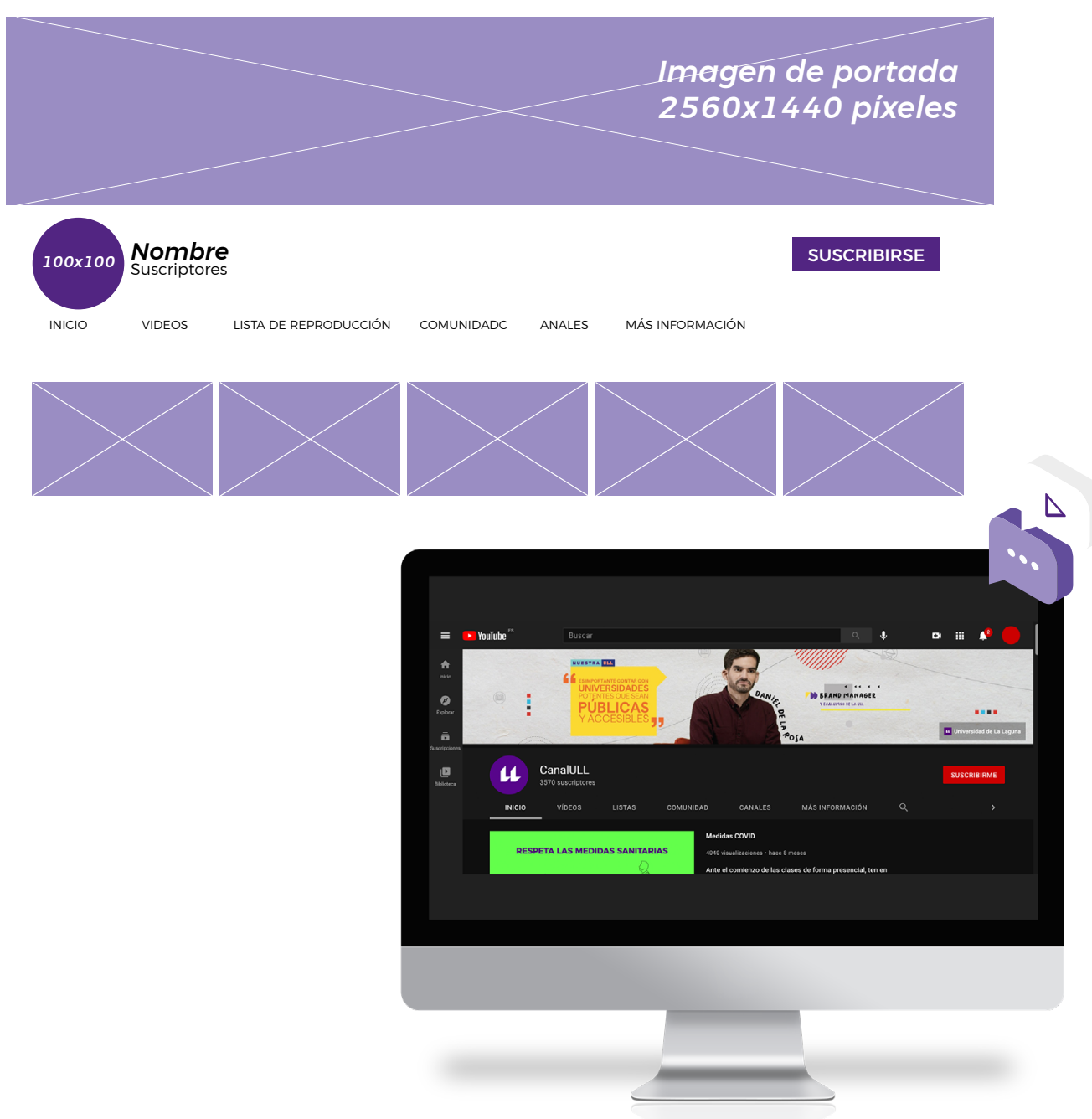


\section{CONTENIDO}

El contenido audiovisual se erige como el más complejo a la hora de crearlo. No obstante, si se gestiona un canal de Youtube, lo ideal sería realizar contenido propio con regularidad y de interés para el público en general. Además, aunque se puedan subir vídeos de amplia duración, lo aconsejable es realizar, por lo general, pequeñas piezas de no más de 5 minutos, salvo que se trate de eventos, charlas, etc.

El contenido ha de ser original y en ningún caso se subirá un vídeo que no sea de nuestra propiedad. Es más, Youtube no permite subir dos vídeos idénticos a la plataforma ni vídeos en los que la música no esté libre de derechos. Por lo tanto, habrá que ser muy cuidadoso al gestionar el canal.

A la hora de subir un vídeo al canal resulta fundamental incorporar un buen título, una descripción adecuada y etiquetas para que tengan un mejor posicionamiento en Google, pudiendo así llegar a un mayor número de personas interesadas.

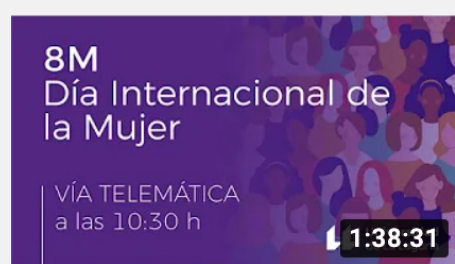

8M Día Internacional de la

Mujer

CanalULL

384 visualizaciones .

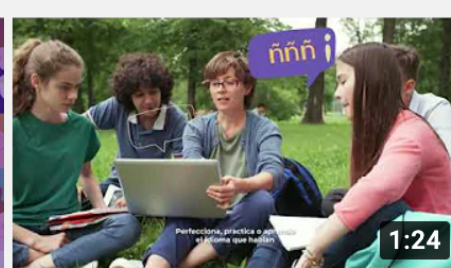

Conoce la Universidad de La Laguna

CanalULL 880 visualizaciones .

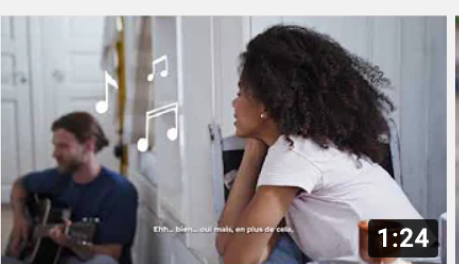

Apprenez à connaître I'Université de La Laguna CanalULL

106 visualizaciones .

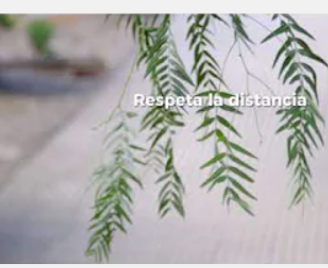

Respeta la distancia personal contra la COVID19

CanalULL

149 visualizaciones .

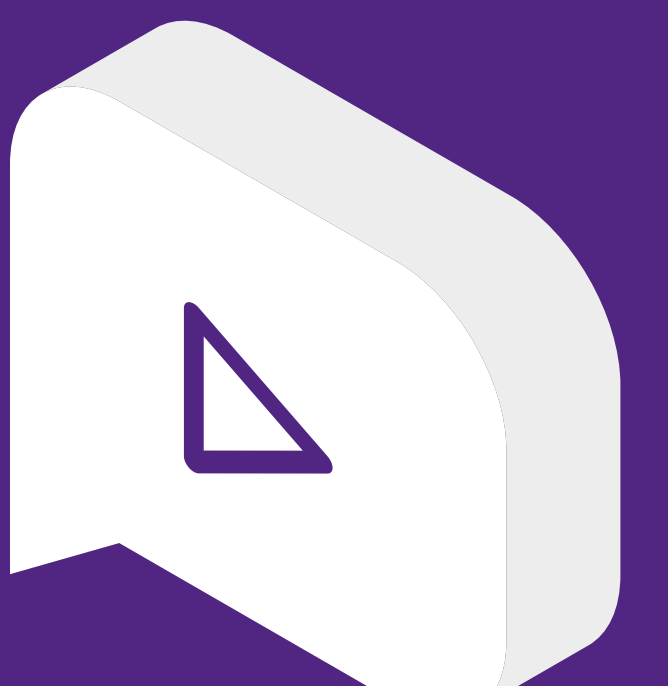

$0: 51$

Lectura del manifiesto por el Día Internacional de la...

CanalULL

323 visualizaciones . 


\section{L I NKED I N}

La red social de profesionales ha ido evolucionando con el paso del tiempo, aunque sin perder su eje principal, generar contenido en torno a empresas, instituciones y trabajadores. La Universidad de La Laguna posee una amplia comunidad en Linkedin, con más de 50.000 seguidores en la página institucional, y desarrolla una clara estrategia a la hora de publicar contenido en ella. Dando por hecho el perfil profesional de sus usuarios, centra sus esfuerzos en la difusión de noticias y reportajes vinculadas con la investigación y el mundo laboral.

\section{Denominación de páginas en Linkedin}

Como se ha comentado en las anteriores redes sociales, el nombre de la página es la carta de presentación de cara a los usuarios, por lo que en Linkedin también debe ser claro, conciso y que represente al centro, facultad, servicio, etc. que vaya a denominar. Por otro lado, en este caso, mantener la información actualizada en la descripción de la cuenta resulta fundamental, probablemente más que en otras plataformas.

\section{Imagen de perfil y de portada}

Linkedin ofrece la posibilidad de usar una imagen para la portada y otra para el perfil. Como ya se ha comentado anteriormente, lo mejor para esa foto de perfil es usar el logotipo de la Universidad de La Laguna. Por su parte, en cuanto a la imagen de portada se refiere, es recomendable emplear una instantánea que represente al centro, facultad, servicio, etc. para el que se haya creado la página.

\section{Características de las imácenes:}

\section{Perfil: $400 \times 400$ píxeles}

Portada: $1584 \times 396$ píxeles in a Buscar

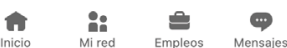

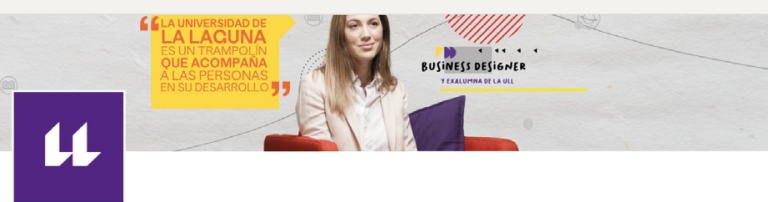

Universidad de La Laguna

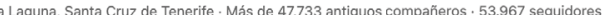

(1. 90 C. C. y 5 contactos más trabajan aquí 2170 empleados

$\checkmark$ Siguiendo Visitar sitio web $\mathrm{E}$ Más

Inicio Acercade

Publica

Empless

\section{CONTENIDO}

Si se desea poner en marcha o continuar gestionando una página de Linkedin, habrá que tener el cuenta el público de esta red social. Por lo tanto, se recomienda que el contenido en general se desarrolle desde el punto de vista laboral y el amplio potencial que puede llegar a tener en usuarios que buscan trabajo o ya no tienen. Centrándonos en el perfil de la Universidad de La Laguna, el tipo de persona que está interesado en seguir lo que se publica en la página institucional serán investigadores, profesorado o personal de administración y servicios, más que alumnado de grado, que aún se encuentra desarrollando sus estudios.

El tipo de publicaciones más comunes en Linkedin se basan en compartir noticias de interés para los usuarios. Además, se le añadirá un pequeño texto descriptivo y si es posible un enlace para ampliar la información. 
RELACIÓN DE REDES SOCIALES DE LA UNIVERSIDAD

DE LA LAGUNA

\section{$\mathbb{L}$}

Universidad de La Laguna

Gabinete de Comunicación

2021 